\title{
Ventral Herniorrhaphy with the Combined Use of Component Separation Technique and Negative Pressure Wound Therapy in Patient with Complex Abdominal Wall Hernia Complicated with Parastomal Hernia: A Case Report
}

\author{
Takeaki Sato, Motoo Fujita and Shigeki Kushimoto \\ Department of Emergency and Critical Care Medicine, Tohoku University Hospital
}

\begin{abstract}
Background

The component separation technique (CST) allows reconstruction of large ventral defects, which may be beneficial under contaminated conditions, but the rate of surgical site infection is relatively high. Negative pressure wound therapy (NPWT) potentially offers better wound closure in such conditions.

We present a patient having multiple complex incisional hernias with parastomal hernias who underwent ventral herniorrhaphy with the combined use of CST and NPWT.
\end{abstract}

\section{Case presentation}

This 78-year-old woman had a history of Hartmann's operation 5 years previously. She was complicated with median incisional hernia and parastomal hernia. We performed herniorrhaphy with stoma closure simultaneously, with CST and NPWT. After colon anastomosis and simple suture repair of the parastomal hernias, her median abdominal wall defects were assessed as $180 \mathrm{~mm}$ at upper and $150 \mathrm{~mm}$ at lower abdomen. Although fascial closure was completed by CST with some tension, dead space remained under the skin and subcutaneous fat layer. Therefore, we combined NPWT on the fascial plane. There was no severe surgical site infection and there was no evidence of hernia recurrence for a year after the operation.

Received: August 23, 2017/ Accepted: November 19, 2017 Correspondence to: Takeaki Sato

Department of Emergency and Critical Care Medicine, Tohoku University Hospital, Sendai,1-1 Miyagi, Japan

\section{Conclusions}

CST followed by NPWT may be an effective alternative for repair of huge and complex incisional hernias, particularly in contaminated conditions.

Key words: incisional hernia, component separation technique, negative pressure wound therapy

\section{Background}

An increasing number of patients have large or complex abdominal wall defects following multiple abdominal operations ${ }^{1)}$. The component separation technique (CST), which was first described in 1990 for midline abdominal wall reconstruction ${ }^{2)}$, is a type of rectus abdominis muscle advancement flap that allows reconstruction of large ventral defects. This technique may be beneficial particularly under contaminated conditions in which the use of prosthetic material is contraindicated ${ }^{3}$. However, the rate of surgical site infection (SSI) is relatively high $^{4)}$, and there is a reported risk of wound necro$\mathrm{sis}^{5)}$.

Negative pressure wound therapy (NPWT) has been suggested to have the potential for better wound closure in such conditions, by assisting wound healing and reducing the tension on the wound, reducing the risk of SSI ${ }^{6}$.

We present a patient having multiple complex incisional hernias with parastomal hernias who underwent ventral herniorrhaphy with the combined use of CST and NPWT, leading to successful closure of the abdominal wall without major complications.

\section{Case presentation}

A 78 -year-old woman, height $152 \mathrm{~cm}$ and body 


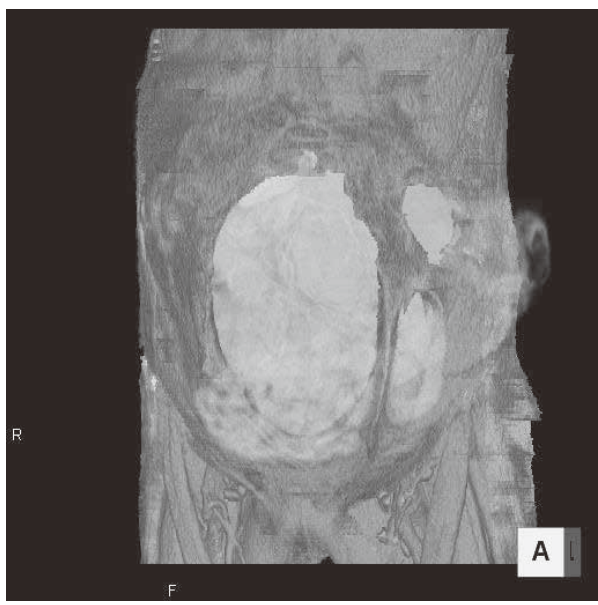

Fig. 1 Preoperative computed tomography findings showed huge midline incisional hernia and parastomal hernia of the oblique muscle at the upper abdomen and rectal muscle at the lower abdomen.

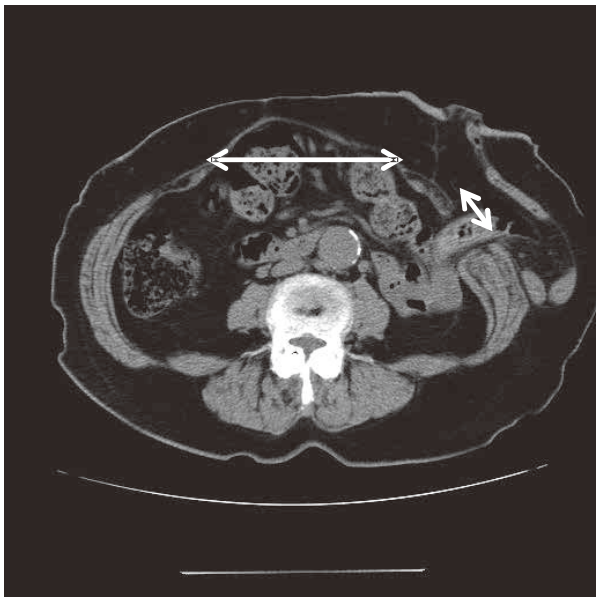

Fig. 2 Preoperative computed tomography findings showed $125 \mathrm{~mm}$ midline and $34 \mathrm{~mm}$ oblique muscle defects at the upper abdomen.

weight $60 \mathrm{~kg}$ (body mass index 26), had a history of Hartmann's operation for idiopathic sigmoid colon perforation, and reconstruction of colostomy due to stomal ischemia 5 years previously. She had been complicated with surgical site infection, and also with median incisional hernia and parastomal hernia. She was admitted to our institution due to parastomal hernia incarceration, which was reduced manually. She had anticoagulant therapy because of

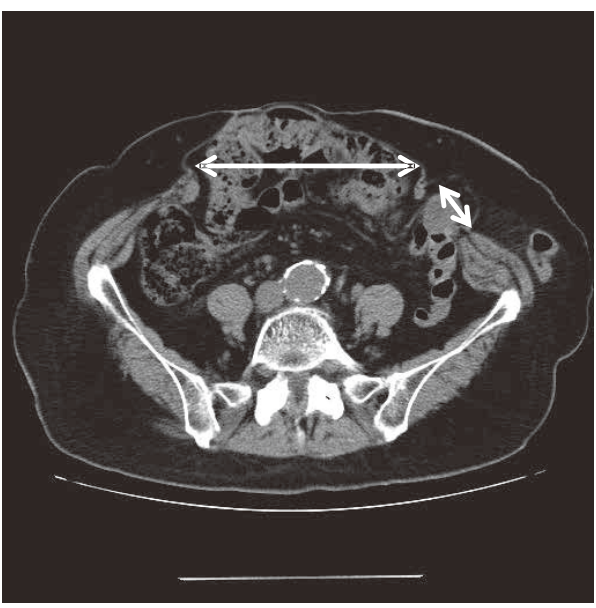

Fig. 3 Preoperative computed tomography findings showed $125 \mathrm{~mm}$ midline and $23 \mathrm{~mm}$ rectal muscle defects at the lower abdomen.

deep vein thrombosis, so we planned to perform herniorrhaphy with simultaneous stoma closure, to reduce the risk of discontinuation of anticoagulant therapy.

There were huge midline incisional and parastomal hernias (Fig. 1). Based on computed tomography assessment, the median abdominal defect was $125 \mathrm{~mm}$ at the level of the upper abdomen and a colostomy was constructed through the oblique muscle with a $34 \mathrm{~mm}$ diameter parastomal hernia (Fig. 2). At the level of the lower abdomen, there were $125 \mathrm{~mm}$ of median defect and $23 \mathrm{~mm}$ of rectal muscle defect (Fig. 3 ).

\section{Surgical procedures}

After descending colon-sigmoid colon anastomosis, the parastomal hernia (oblique muscle) and ex-stomal hernia (rectal muscle) orifices were closed with simple suture repair by non-absorbable thread without excess tension.

Under general anesthesia with abdominal muscle relaxation, the median abdominal wall defects were assessed as $180 \mathrm{~mm}$ at upper and $150 \mathrm{~mm}$ at lower abdomen (Fig. 4) after the repair of para- and exstomal hernias. For the component separation procedures, anterior CS: incisions were made bilaterally in the external oblique aponeurosis $2 \mathrm{~cm}$ lateral to the border of the rectus and external oblique muscles (Fig. 5). It was not enough to close safely, so we added posterior CS: the posterior rectus sheath 


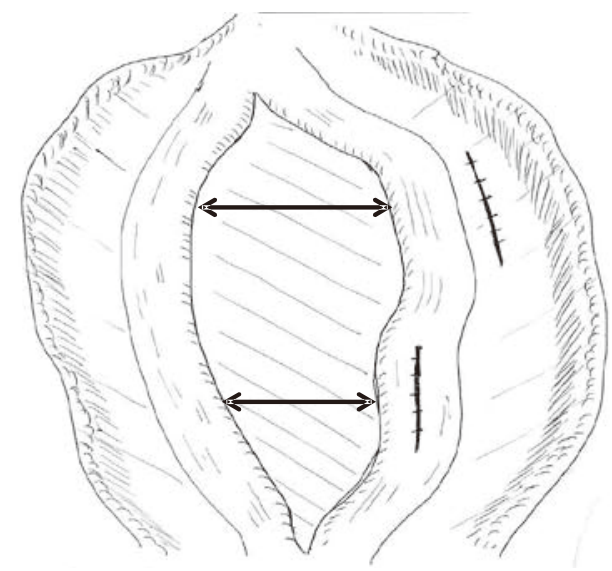

Fig. 4 Schema of intra-operative findings after simple suture repair of oblique and rectal muscles. Midline defect was $180 \mathrm{~mm}$ at the upper abdomen (upper arrow), and $150 \mathrm{~mm}$ at the lower abdomen (lower arrow).

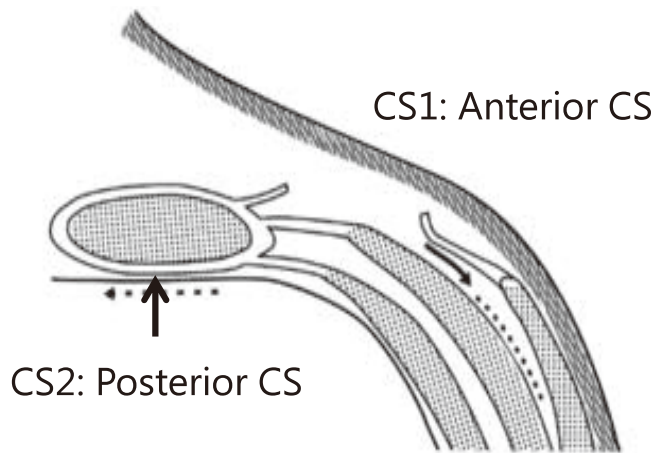

Fig. 5 Schema of component separation technique. Anterior component separation (CS1): incisions were made in the external oblique aponeurosis next to the border of the rectus and external oblique muscles, and bluntly dissected. Posterior component separation (CS2): the posterior rectus sheath was incised and extended. The same procedure was repeated on the other side.
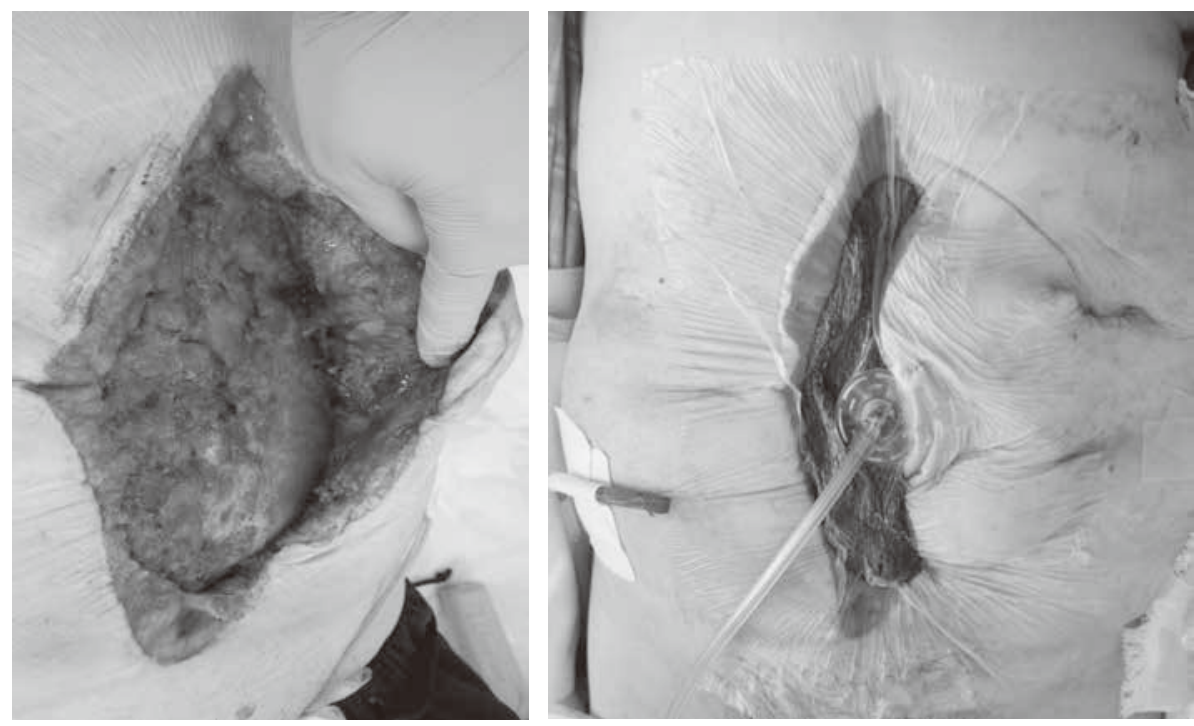

Fig. 6 Postoperative findings of abdominal wall. There was a large area under the skin (left). NPWT was employed to shore up the abdominal wall (right).

was also incised at approximately 0.5 to $1 \mathrm{~cm}$ from the medial edge of the rectal muscle, besides the site of parastomal hernia repair, and the plane was bluntly developed between the transverse abdominis muscle and the transversalis fascia/peritoneum.

We close the abdominal wall with non-absorbable thread, knotted suture, at intervals of $1 \mathrm{~cm}$, with the bite of $1 \mathrm{~cm}$. Although fascial closure was completed, the closure required moderate tension, particularly in subcostal and inguinal areas. There were little gap between the stitch, with possible dead space under the skin and subcutaneous fat layer (Fig. 6).

As a result, we made broad exfoliation under the 


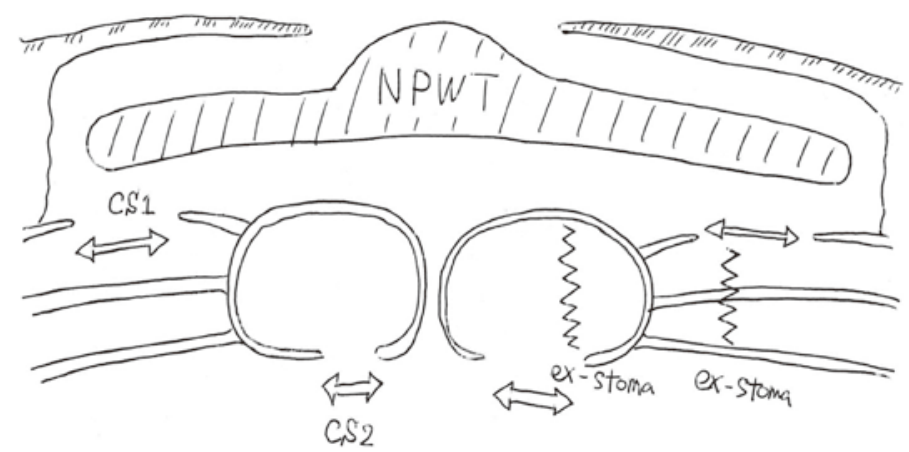

Fig. 7 Scheme of NPWT+CS: CS1, anterior component separation, CS2, posterior component separation. The sponge form of NPWT was placed on the muscle wall under the skin flap, to reinforce the sites of ex-stoma, median wall closure and component separations and to reduce the dead space.

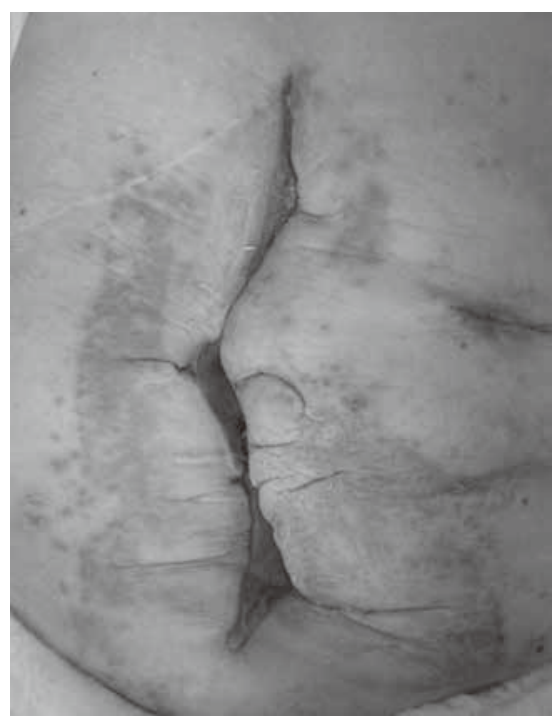

Fig. 8 State after NPWT: the fascia was covered, and there was contact dermatitis from the wound dressing.

skin to perform CSs. We tried to keep skin perforator vessels and inferior epigastric artery as possible to prevent tissue necrosis.

Therefore, we combined NPWT with a V.A.C. therapy system (KCI Japan Co., Ltd., Fig. 7). We put sponge form (to apply negative pressure) below the skin flap and apply to the surface of the fascia. The continuous negative pressure was provided at $125 \mathrm{~mm} \mathrm{Hg}$. The dressing and tubing were changed every 2 days, and gradually approximated the skin flap. We continued NPWT for 14 days and we could avoid the skin necrosis, rectal muscle necrosis, and seroma formation.

She was discharged 17 days after her operation. The wound shrank and granulation tissue covered the fascia (Fig. 8), making it difficult to suture the skin. A month after operation, the wound closed spontaneously.

There was no evidence of incisional hernia for a year after operation.

\section{Discussion}

Incisional hernias arise due to failure of fascial tissues to heal and close following laparotomy, which may be related with surgical site infection ${ }^{1}$. Mesh repairs are generally preferred to simple non-mesh closure, but in contaminated conditions, artificial materials may be contraindicated ${ }^{7}$. Patients undergoing Hartmann closure are at risk for SSI, particularly in obese patient ${ }^{8)}$.

Advantages of CST include restoration of functional and structural integrity of the abdominal wall, provision of stable soft tissue coverage, and optimal aesthetic appearance without using prosthetic materials for patients with complex and/or large ventral hernias ${ }^{2}$. However, there are risks of surgical site infection (particularly in obese patients) ${ }^{9)}$, seroma and hematoma ${ }^{3)}$, rectal muscle and skin flap necrosis with $\mathrm{CST}^{10)}$.

NPWT can have a beneficial effect for wounds in which infection is suspected, by decreasing the dead space, reducing local edema, enhancing the blood flow, forming granulation tissue, and clearing of the 
tissue bacteria ${ }^{11}$. These potential effects may complement the adverse sequelae of CST performed under excessive tension and contaminated conditions for huge and complex hernias, as demonstrated in the present patient.

We followed her for a year after operation in emergency department. If recurrence of hernia occurred, mesh repair should be planned.

\section{Conclusions}

The component separation technique followed by negative pressure wound therapy may be an effective alternative to repair of huge and complex incisional hernias, particularly in contaminated conditions.

Conflict of interest: None.

\section{References}

1) Itatsu K, Yokoyama $Y$, Sugawara G, et al : Incidence and risk factors for incisional hernia after abdominal surgery. Br J Surg 101 : 1439-1447, 2014

2) Ramirez OM, Ruas E, Dellon AL:"Component separation" method for closure of abdominal-wall defects: An anatomic and clinical study. Plast Reconstr Surg $86: 519-526,1990$

3) de Vried Reilingh TS, van Goor H, Rosman C, et al : "Component separation technique" for the repair of large abdominal wall hernias. J Am Coll Surg 196 :
32-37, 2003

4) Lowe JB, Garza JR, Bowman JL, et al : Endoscopically assisted "component separation" for closure of abdominal wall defects. Plast Reconstr Surg 105 : 720-729, 2000

5) Torregrosa-Gallud A, Sancho Murriel J, Bueno-Liedo J, et al : Modified components separation technique : experience treating large, complex ventral hernias at a University Hospital. Hernia 2017; doi: 10.1007/ s10029-017-1619-6.

6) Horch RE : Incisional negative pressure wound therapy for high-risk wounds. J Wound Care $24: 21-28$, 2015

7) Perez-Kohler B, Bayon Y, Bellon JM : Mesh infection and hernia repair : a review. P Surg Infect (Larchmt) $17: 124-137,2016$

8) Brathwaite S, Latchana N, Esemuede I, et al : Risk factors for surgical site infection in open and laparoscopic Hartmann Closure : a multivariate analysis. Surg Laparosc Endosc Percutan Tech 27:51-53, 2017

9) Levi B, Zhang P, Lisiecki J, et al: Use of morphometric assessment of body composition to quantify risk of surgical-site infection in patients undergoing component separation ventral hernia repair. Plast Reconstr Surg $133: 559 \mathrm{e}-566 \mathrm{e}, 2014$

10) Orgill DP, Manders EK, Sumpio BE, et al : The mechanisms of action of vacuum assisted closure: more to learn. Surgery $146: 40-51,2009$

11) Morykwas MJ, Arqenta LC, Shelton-Brown EI, et al:Vacuum-assisted closure: a new method for wound control and treatment: animal studies and basic foundation. Ann Plast Surg 38:553-562, 1997 